\title{
Reflections on Beauty: Immanuel Kant and Semir Zeki
}

\author{
Michaela Rušinová
}

\begin{abstract}
The presented paper concerns the issue about constitutive groundings of aesthetic experience in the framework of insights proposed by Immanuel Kant and Semir Zeki. According to Kant, aesthetic experience is a matter of reflexive judgment and a free play of cognitive faculties while experiencing a beautiful object. Kant's transcendental position has been transformed, as it is suggested, into the neuroaesthetics of Zeki with an assumption that mind - in Kant's conception - might be understood as brain and thus, the brain is a subject to the constitution of beauty. The main argument in the paper is that the cognitive competence of the brain gives rise not only to the knowledge, but also to beauty that is in the mind and brain of the beholder.
\end{abstract}

Keywords—beauty, brain, concept, judgment

\section{INTRODUCTION}

$\mathrm{W}$ HEN we are facing a beautiful object, we are pleased with perceiving it. We enjoy what we experience and we appreciate it. I suppose that beauty is principally connected with positive emotions. Ugliness can also attract our attention, but in contrast to the aesthetic experience, it can also cause fear or disgust. However, an object that is perceived to be beautiful should provide the feeling of pleasure, whether it is an attractive human face or body, a lovely decoration, sublime mountains, an impressive work of art or an compelling idea. While having an aesthetic experience, the subject likes the experiential content in the form of a mental representation. What we judge as beautiful is something that is presented to our senses or has a direct source in our minds.

It is possible to ask: is beauty an intrinsic quality of an aesthetic object as such or is it rather a matter of our taste and our recognition of an object as being beautiful? To put it in other words, the issue refers to the question, whether beauty is an objective property of objects or rather a subjective appraisal that depends on subject's own cognitive capacities? If beauty could be seen as an objective property of objects, it would be considered as beautiful by all humans. This seems to be misleading, since there is not any universal agreement declaring what is beautiful par excellens. Claude Monet's paintings might be for somebody beautiful while for other person not. Since there is a great doubt about beauty as

Michaela Rušinová is with the Department of Philosophy, Trnava University in Trnava, Trnava, 918 43, Slovakia (e-mail: rusinova.michaela@hotmail.com).

This work was supported by the Slovak Research and Development Agency under the contract No. APVV-15-0294. something independent from the perceiver, we should formulate the initial question in a different way, focusing on reasons why there is disagreement among people about the instantiation of beauty. Is there a common characteristic among the variety of different objects that are judged to be beautiful or depends our taste on individual's cognitive abilities? This leads also to the question, whether our aesthetic experience might be influenced by conceptual knowledge that we possess?

I would like to discuss this problem from the philosophical point of view. Mainly with reference to Kant's and Zeki's ideas on this topic with an attempt to argue, that aesthetic experience exhibits our cognitive faculties, namely the capability of formation of the meaning and the conceptual knowledge. The main aim is to show that there is an "open space" in the matter of application of subject's cognitive abilities in the case of having aesthetic experience, as both authors claim. In connection to this I would like to clarify the underlying mechanisms of cognitive processes that might stand for the capability of grasping the notion beauty.

\section{EMOTIONAL AND COGNITIVE ASPECTS OF AESTHETIC EXPERIENCE}

As it has been portrayed in the introduction, aesthetic experience is accompanied by emotions connected with perception of something that the subject evaluates as beautiful. This is the reason why the contemporary literature distinguishes between an attentive, a cognitive and an affective moment within the aesthetic experience [3]. Fascination with particular object fixates person's attention and appealing to an aesthetic object is felt as something exceptional, delightful and so forth; therefore, the emotional component of an aesthetic experience seems to be the leading one and will not be discussed in a greater detail in this paper. The cognitive component of an aesthetic experience is, as I have suggested, the most problematic part in the description of an aesthetic experience - to what extent the aesthetic experience engages our cognition and to what extent it can enhance our knowledge?

Cognition, as defined by Kant in his Critique of Pure Reason, has two sources: the receptivity of impressions and the spontaneity of concepts that is ascribed to the faculty of understanding [1]. Concepts are understood as functions of "ordering different representations under a common one" [1, B93, p. 205], so accordingly the mind makes the judgment. Kant therefore terms the understanding as a faculty of judgment. In his Critique of Judgment he claims that 
"Judgment in general is the ability to think the particular as contained in general" [2, p. 18]. He stands for a traditional approach when he ascribes the character of the concepts, as to be predicates of the possible judgments.

The knowledge is possible only in the unification of various representations under a certain concept (or various concepts) that is carried out by judgments. Our understanding is guided by concepts that we possess, otherwise we do not know, in the case of having sensory experience, what we actually perceive. In the case when we already have concepts and we apply them on representations - the judgment is determinative, as it is claimed by Kant [2]. By possessing a certain concept, the subject knows a rule through which then he/she is able to subsume multiple representations under this concept, and thus identifies them as having some common features. The subjects do so not only when they are reasoning something, but this process is also applied in ordinary perception when we are able to classify the perceived objects; subjects are able to distinguish objects presented, for instance, in their visual experience - they are capable to perceive a table and discern it from a chair, a computer, a book and a pen. In general, we might say that the concepts organize the representations.

This is the key point in our discussion speaking about beauty. Kant believes that what is subjective on each representation is its aesthetic character which is connected with the pleasure or displeasure [2]. A fundamental notion in the case of aesthetic experience is a formal purposiveness of an aesthetic object that consists in the feeling of pleasure [2]. Our aesthetic judgment, the judgment of taste, is not determinative but reflective, and is based on consonance of our imagination and understanding [2]. To interpret Kant, what makes the given representation beautiful? He would answer that it is the way how the representation is organised in its formal structure. One of the consequences is that an object of aesthetic experience causes joy in subjects independently from what we know about it. The second one is that we are not able to explain exactly why we like particular object. We may find million words to describe the object of beauty and still we may find out that it is not sufficient for expression of the pleasure we feel; but also we may just gaze on it, without any speech and thoughts. This is the reason why he states that "Beautiful is what, without a concept, is liked universally" [2, p. 64]. Universality of the judgment about beauty among humans is, according to Kant, guaranteed by the fact that all human beings possess the idea of higher purposiveness as a form of sensus communis based on the pleasure itself. The purpose of aesthetic object is that it is liked without any other functions. Important is that an idea of beauty is not fixed on a particular empirical instantiation of beauty in terms of an aesthetic ideal [2], since ideal may vary among individuals and cultures as a matter of taste, but the feeling of pleasure from perceiving of beauty is common to all humans.

Although Kantian positions were formulated more than two centuries ago it seems that his conception is still "fresh". Semir Zeki in his work Splendors and Miseries of the Brain directly refers to Kant thoughts and suggests that what Kant means by "mind" (as a disposition to cognize the reality) can be understood as a brain. According to Zeki: "All knowledge is brain knowledge" [4, p. 21]. Principal function of the brain is the acquisition of knowledge and the formation of concepts, either more concrete (such as "face", "body") or abstract (such as the concept of "beauty", "truth" and so forth); and due to these concepts brain organizes an incoming signals into a meaningful percept [4]. The ability to perceive constancy of objects (their form and relating properties) and to capability to distinguish between various kinds of representations is also ascribed to the competence of brain architecture, that is, uniform among humans [4]. Therefore, Zeki supposes the existence of so-called inherited brain concepts (e.g. "color" or "unity-in-love") and acquired brain concepts (e. g. "plane"); and this distinction matches with Kant's a priori and $a$ posteriori concepts. The main difference between Kant and Zeki is that while Kant supposes the idea of beauty as independent from all previous experience, Zeki claims that "Our concept of what is beautiful changes as we view more and more objects or situations, or as we find ourselves in different cultural environments" [4, p. 44]. Kant would term this as an ideal that is not identical among individuals but the idea of beauty remains unharmed. The basic challenge for Kant, in my view, is to defend this assumption about the general validity of judgment of taste, since taste seems not to be the same among people and is rather a matter of experience as well as the judgment about beauty. As it is supposed by Zeki, there is a tendency of the brain to find perfection in the reality even if it is merely a construct of the brain [4]. This might be interpreted as a "free" realisation of the imagination within the frame of brain's conceptual competence.

\section{CONCLUSION}

To sum up, the paper has briefly discussed the subject's mind or, analogically, the subject's brain as executive faculty in the case of aesthetic experience. According to the analysis of Kant and Zeki's thoughts, beauty is a matter of subjective feeling and evaluation of the object. The paper has showed several similarities and distinctions between Kant and Zeki in the question about the groundings of aesthetic experience.

\section{REFERENCES}

[1] I. Kant, Critique of Pure Reason. Transl. P- Guyer, A. J. Wood, Cambridge: Cambridge University Press, 1998. https://doi.org/10.1017/CBO9780511804649

[2] I. Kant, Critique of Judgment. Transl. W. S. Pluhar, Cambridge: Hackett Publishing Company, 1987.

[3] S. Markovič, "Components of aesthetic experience: aesthetic fascination, aesthetic appraisal, and aesthetic emotion," Iperception, vol. 3, no. 1, pp. 1-17, Jan. 2012. https://doi.org/10.1068/i0450aap

[4] S. Zeki, Splendors and Miseries of the Brain. Oxford: Blackwell, 2009. 